\title{
Immunolocalisation of the VEGF receptors FLT-1, KDR, and FLT-4 in diabetic retinopathy
}

\author{
Gillian Smith, David McLeod, David Foreman, Mike Boulton
}

\begin{abstract}
Aim-To determine the spatial and temporal changes in the staining pattern of the VEGF receptors FLT-1, KDR, and the putative receptor FLT-4 during the pathogenesis of diabetic retinopathy.

Methods-Immunohistochemical localisation of VEGF receptors, using antibodies against FLT-1, FLT-4, and KDR, was carried out on specimens of normal human retina $(n=10)$, diabetic retinas (a) with no overt retinopathy $(n=12),(b)$ with intraretinal vascular abnormalities but no proliferative retinopathy $(n=5)$, (c) with active proliferative retinopathy $(n=6)$, and (d) with no residual proliferative retinopathy after scatter photocoagulation therapy $(n=14)$, and surgically excised diabetic fibrovascular membranes $(n=11)$. The degree and pattern of immunostaining was recorded.
\end{abstract}

Results-FLT-1 staining was apparent in the retinas from both non-diabetic and diabetic retinas; weak to moderate staining was generally confined to the inner nuclear layer, the ganglion cell layer, and the retinal vessels during all stages of the disease process. Staining of the retinal vessels was raised in diabetic tissue compared with non-diabetic tissue. The preretinal vessels of the diabetic subjects stained moderately to intensely for FLT-1. In contrast with FLT-1 staining minimal immunostaining for KDR was demonstrated in the non-diabetic eyes and the unlasered eyes; however, weak staining for KDR was observed in the inner nuclear layer and the ganglion cell layer of the unlasered eyes with diabetic changes. In those retinas with preretinal neovascularisation KDR immunoreactivity was moderate to intense in the intra- and preretinal vessels. However, in the excised membranes, where the vessels may have been in a quiescent state, the levels of KDR were weak to moderate. After apparently successful laser treatment KDR staining was reduced in the intraretinal vessels. Minimal FLT-4 staining was observed throughout normal eyes while weak to moderate FLT-4 staining was generally confined to the inner nuclear layer and the ganglion cell layer of the unlasered diabetic eyes. Weak to moderate levels of FLT-4 staining were observed in the intraretinal vessels except after apparently successful laser treatment where reduced levels of staining were observed. Weak to moderate staining was observed in the preretinal vessels.

Conclusions-This study supports a role for FLT-1, KDR, and possibly FLT-4 in the pathogenesis of diabetic retinopathy; however, their specific roles in the progression of the disease may differ.

(Br f Ophthalmol 1999;83:486-494)

Proliferative diabetic retinopathy (PDR), the archetypical vasoproliferative retinopathy (VPR), is characterised by preretinal neovascularisation and fibrosis, ultimately leading to vitreous haemorrhage and traction retinal detachment. ${ }^{1}$ A number of growth factors have been implicated in PDR of which vascular endothelial growth factor (VEGF) is considered to be of major importance since (a) it is a diffusible factor, ${ }^{2-4}$ (b) it increases vascular permeability, ${ }^{2-5}$ (c) it modulates angiogenesis, ${ }^{2-4}$ (d) it stimulates endothelial cell proliferation $^{2-4}{ }^{6}$ and migration, ${ }^{6}$ (e) it is upregulated in response to hypoxia, ${ }^{7-9}$ and (f) agents which inhibit the binding of VEGF to its receptors have been demonstrated to reduce neovascularisation. ${ }^{11}{ }^{11}$ In situ hybridisation, northern blotting, and immunohistochemistry have demonstrated increased expression of VEGF in animal models for VPRs ${ }^{812}$ and in diabetic human retinas. ${ }^{8}{ }^{13-16}$

VEGF is believed to act through high affinity receptors located on endothelial cells. ${ }^{236}$ These receptors are autophosphorylating type III tyrosine kinases and consist of $\mathrm{KDR}$ (FLK-1 in mouse, TKrC in rats, Quek1 and 2 putative avian $^{5}$ ) and FLT-1 receptors. ${ }^{23}$ Both receptors are characterised by the presence of seven immunoglobulin-like domains in their extracellular region ${ }^{2}$ and are expressed during embryogenesis where they appear to play an important role in endothelial growth and differentiation during vasculogenesis and angiogenesis. ${ }^{17}{ }^{18}$ FLT-1 is believed to regulate metabolic activity including vascular permeability while KDR is considered to modulate angiogenic responses (for example, endothelial cell migration and proliferation). The importance of FLT-1 is further inferred by the recent demonstration that placenta growth factor (PlGF) is associated with diabetic retinopathy; ${ }^{19}$ PIGF acts through the FLT-1 receptor. ${ }^{20} \mathrm{~A}$ third tyrosine kinase receptor may be important in VEGF recognition by endothelial cells; FLT-4, which has a similar structure to FLT-1 and KDR, is expressed in the placenta and in several mouse tissues during embryogenesis. ${ }^{21} 22$

Although there are a large number of reports documenting upregulation of VEGF mRNA 
and protein in the VPRs there is very little information on the profile of VEGF receptors. In this study we used immunohistochemistry to detect FLT-1, KDR, and FLT-4 protein in (a) normal human retinas, (b) diabetic retinas with various stages of retinopathy, and (c) in preretinal fibrovascular membranes excised during diabetic vitrectomy.

\section{Materials and methods}

DONOR EYES

A total of 47 eyes enucleated and fixed in $10 \%$ neutral buffered formalin, within 10 hours post mortem, were obtained from the National Disease Research Interchange (NDRI), Philadel-
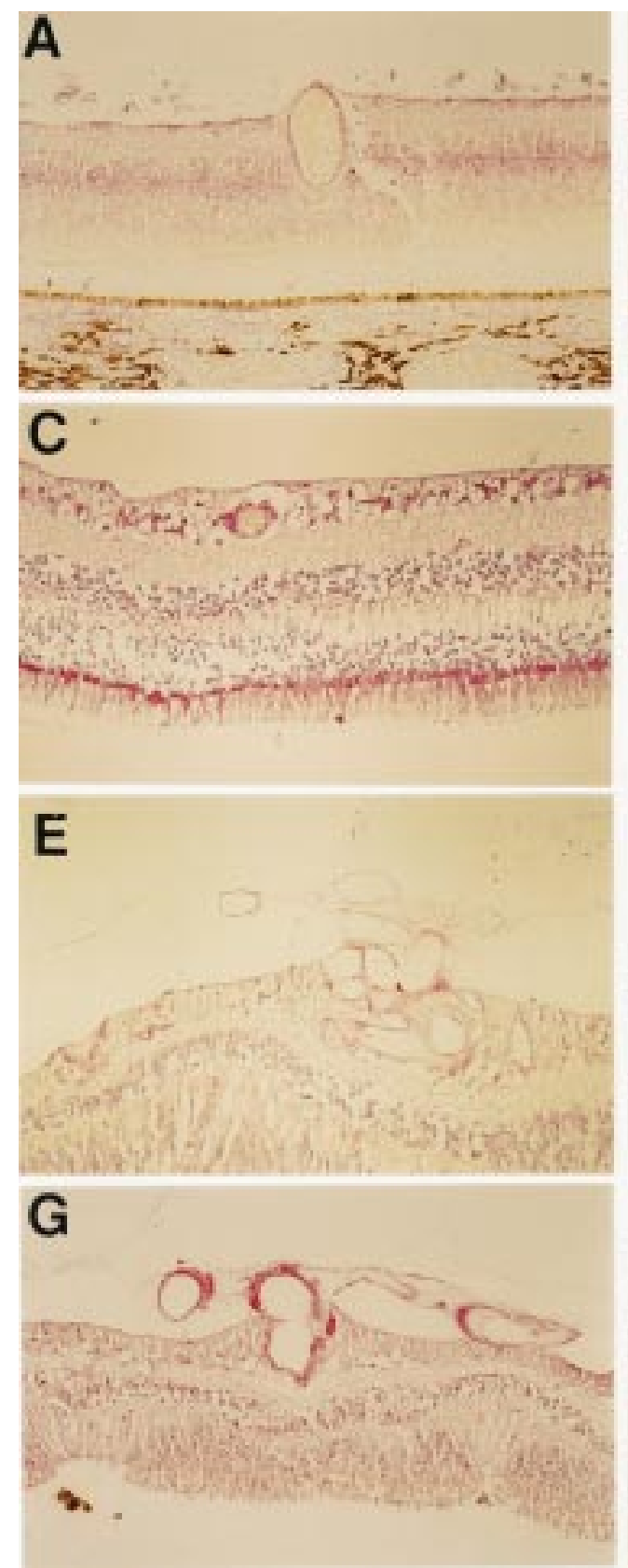

phia, USA. Each eye was dissected into an anterior and posterior segment. A complete medical history was not available for all donors but details were available regarding glycaemic management. Of the 37 diabetic donors 25 had been injecting insulin for at least 6 months (mean age 62 years) and 12 were not receiving insulin treatment but did use oral hyperglycaemic drugs (mean age 65 years). Examination of the posterior segment was performed by an ophthalmologist (DM) using a Zeiss Stemi SV8 zoom dissecting microscope with Schott light source (a) to note overt features of retinopathy (for example, the presence of preretinal membranes, cotton wool spots, microaneurysms,
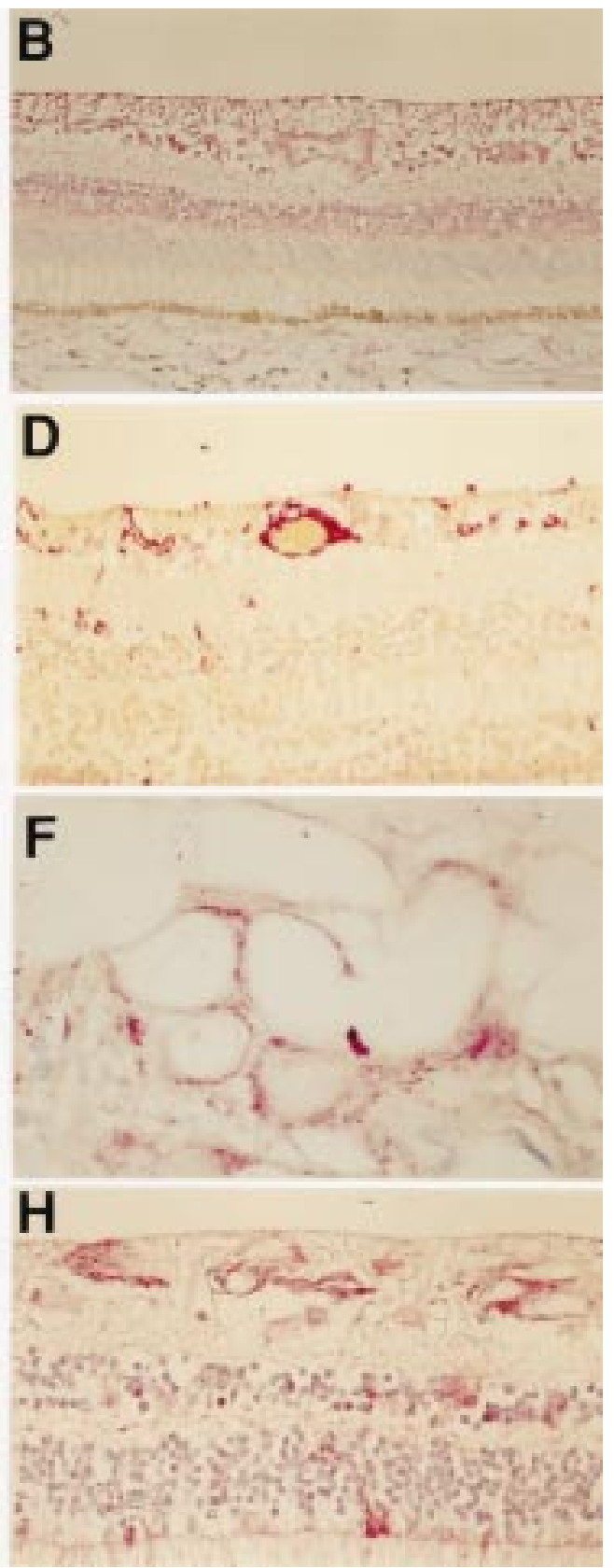

Figure 1 Photomicrographs demonstrating FLT-1 immunostaining of non-diabetic retina $(A)$, diabetic retina with no obvious retinopathy $(B)$, diabetic retina with obvious intraretinal vascular changes but no evidence of $P D R(C)$, the same retina stained with GFAP $(D)$, diabetic retina with $P D R(E, F, G)$, diabetic retina post laser but with no residual PDR (H). Immunostaining for FLT-1 was greatest in the diabetic tissue compared with non-diabetic tissue. Increased staining was generally confined to the inner nuclear layer and the ganglion cell layer. Magnification $A, G \times 94 ; B, C, E \times 118 ; D$ $\times 156 ; F \times 378 ; H \times 236$. 
etc) and (b) to determine the extent of any scatter photocoagulation.

Eyes were categorised as follows:

Normal-10 human eyes with no known ophthalmic disease, no history of diabetes, and no abnormalities on biomicroscopy. Donors ranged in age from 34 to 89 years (mean 69 years).

Diabetic with no overt retinopathy - 12 human eyes from diabetic donors with no clinical history and no overt biomicroscopic features of retinopathy or retinal photocoagulation. Donors ranged in age from 57 to 89 years (mean 77 years), five had been injecting insulin and seven had not. A complete medical history was unavailable for all donors but, in those where medical histories were known (10/12), the duration of diabetes was between 6 and 10 years (mean 7.3 years).

Diabetic with intraretinal changes but no evidence of PDR - five human eyes from diabetic donors with intraretinal changes on biomicroscopy but no clinical history or overt features of PDR or retinal photocoagulation. Retinas exhibited cotton wool spots and/or obvious microaneurysms or haemorrhages. Donors ranged in age from 62 to 96 years (mean 74 years), three had been injecting insulin and two had not. A complete medical history was known for four donors, the duration of diabetes being between 3 and 21 years (mean 13 years).

Diabetic with preretinal PDR - six human eyes from diabetic donors defined clinically as having PDR and exhibiting preretinal membranes when examined by biomicroscopy. All eyes had previously received laser photocoagulation. Donors ranged in age from 37 to 76 years (mean 58 years), all had been injecting insulin. Duration of diabetes ranged from 3-29 years (mean 14.3 years).

Diabetic with scatter laser photocoagulation but no evidence of residual PDR-14 human eyes

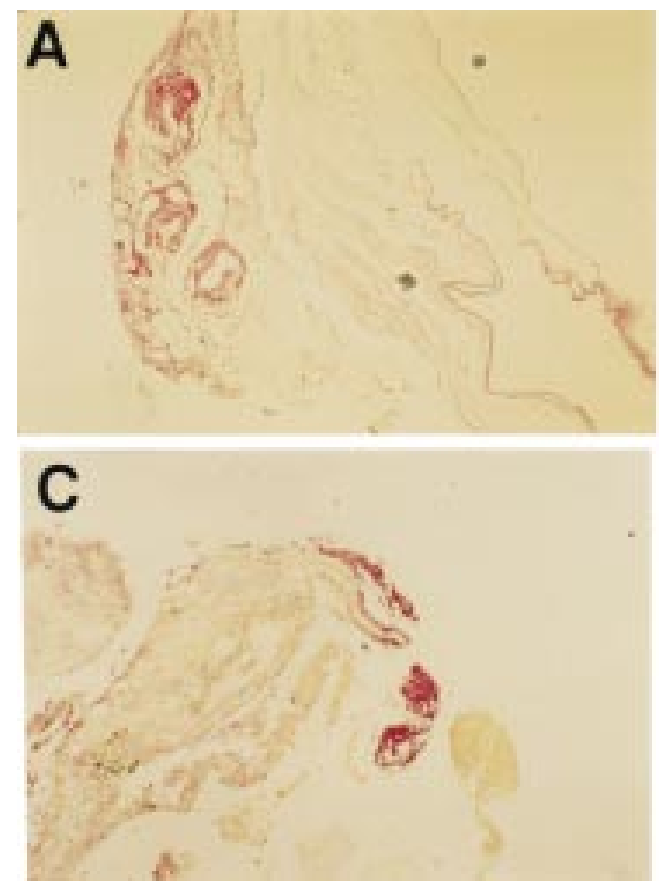

from diabetic donors defined clinically as having had PDR and having received scatter laser photocoagulation. No preretinal membranes could be observed when retinas were examined by biomicroscopy. Donors ranged in age from 40 to 82 years (mean 57 years), 11 had been injecting insulin and three had not. A complete medical history was known for 13 donors, the duration of diabetes being between 10 and 35 years (mean 20 years).

The posterior segment of each eye was cut in the sagittal plane through the centre of the optic nerve head. Cuts were then made perpendicular to this line (a) on the horizontal midline on the nasal side and (b) at approximately $5 \mathrm{~mm}$ above and below the midline on the temporal side. A final vertical cut was made parallel to the initial cut and approximately $3 \mathrm{~mm}$ temporal to the macula. For this study tissue was wax embedded and $5 \mu \mathrm{m}$ sections were cut from a portion of retina/choroid/sclera (a) approximately $3 \mathrm{~mm}$ lateral to the macula and perpendicular to the horizontal plane (this region was chosen because of its susceptibility to retinal changes associated with diabetes) and (b) other representative areas across the retina (for example, areas of neovascularisation).

Fibrovascular membranes-11 fibrovascular preretinal membranes excised at vitreous surgery from eyes with PDR were obtained from the Manchester Royal Eye Hospital. Membranes were fixed in $10 \%$ neutral buffered formalin immediately upon removal and for a minimum of 12 hours before wax embedding.

\section{IMMUNOHISTOCHEMISTRY}

Immunohistochemistry was undertaken as previously described. ${ }^{16}$ The $5 \mu \mathrm{m}$ sections were cut and mounted on APES (Sigma) coated slides. Sections were dewaxed and rehydrated. They were blocked for 60 minutes with $10 \%$ milk protein (Marvel)/normal goat serum (Sigma) before incubation overnight at $4^{\circ} \mathrm{C}$

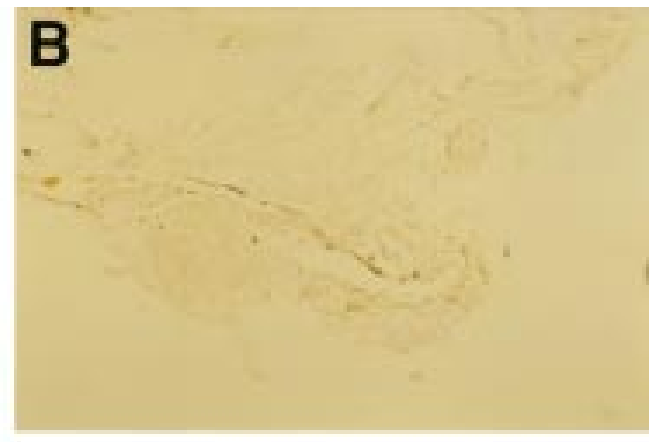

Figure 2 Photomicrographs demonstrating FLT-1 immunostaining of an excised fibrovascular membrane $(A)$. Immunoreactivity for FLT-1 was abolished in a control specimen of excised membrane processed with omission of the primary antibody $(B)$ and GFAP staining of the same excised membrane (C). Intense staining was observed around the vessels in excised membranes. Magnification $A$, $B, C \times 60$. 
with either (a) a polyclonal rabbit antibody raised against a peptide corresponding to amino acids 1312-1328 mapping at the carboxy terminus of FLT of human cell origin and reacting with FLT of mouse, rat, and human cell origin ( $R \& D$ Systems) diluted to 1 $\mu \mathrm{g} / \mathrm{ml}$ in TRIS buffered saline (TBS), (b) a polyclonal rabbit antibody raised against a GST fusion protein containing FLK-1 sequences corresponding to amino acids 1158 1345 mapping at the carboxy terminal of FLK-1 of mouse origin (that is, the murine form of $\mathrm{KDR}$ ) and reacting with FLK-1 of mouse, rat, and human cell origin (R\&D Systems) diluted to $2 \mu \mathrm{g} / \mathrm{ml}$ in TBS, or (c) a polyclonal rabbit antibody raised against a peptide corresponding to amino acids 12791298 mapping at the carboxy terminus of FLT-4 of human origin and reacting with FLT-4 of human origin (R\&D Systems) diluted to $1 \mu \mathrm{g} / \mathrm{ml}$ in TBS. A selection of slides were also stained for polyclonal rabbit antiglial fibrillary acidic protein (GFAP) antibody isolated from human spinal cord, directed against the $56 \mathrm{kD}$ GFAP protein and reacting

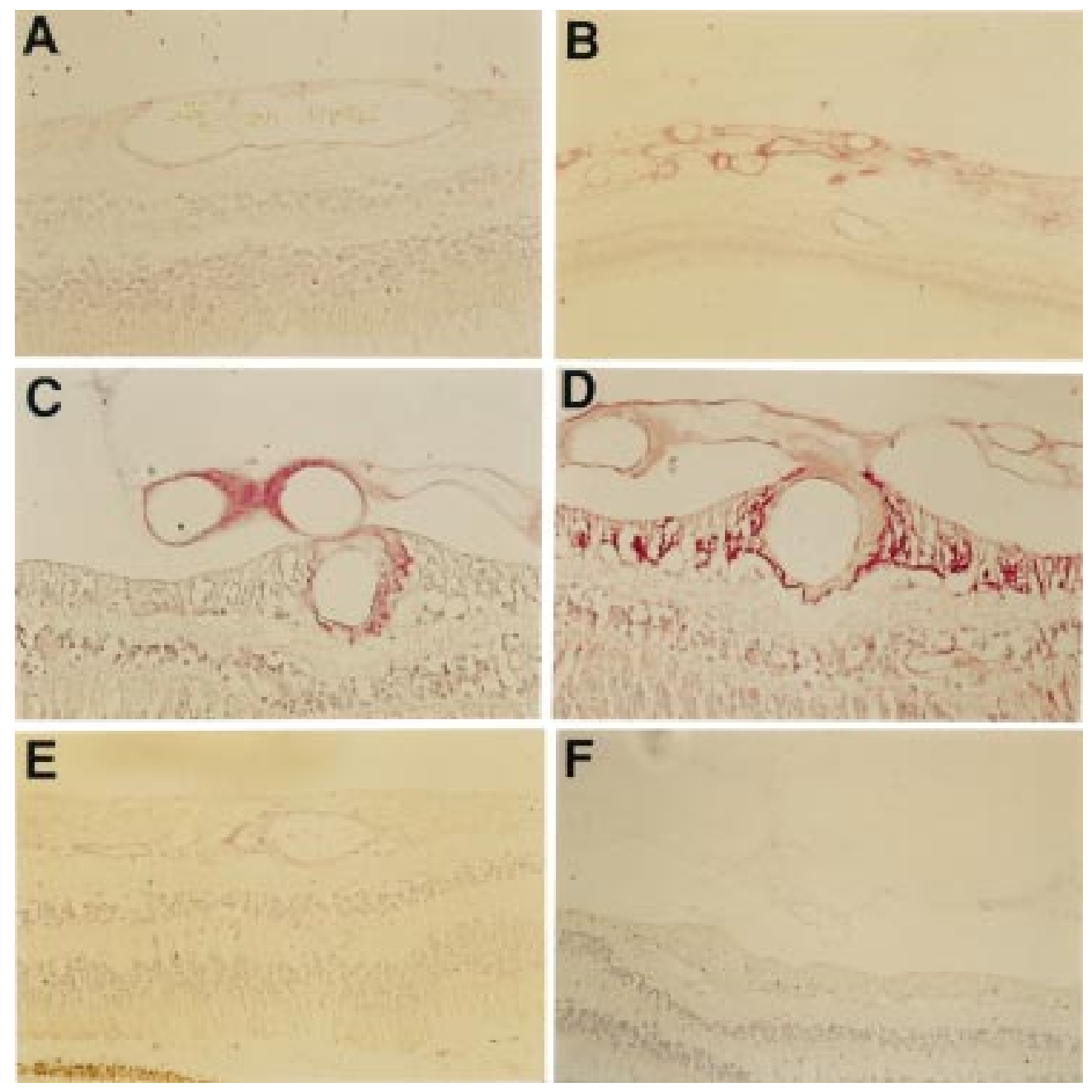

Figure 3 Photomicrographs demonstrating KDR immunostaining of non-diabetic retina $(A)$, diabetic retina with PDR $(B, C)$, the same retina stained with GFAP (D), and diabetic retina post laser but with no residual PDR $(E)$.

Immunostaining for KDR was greatest in the diabetic tissue with PDR and was minimal in most other diabetic tissue. Interestingly, immunostaining in the diabetic retinas which had undergone apparently successful laser treatment was reduced compared with the staining intensity in the retinas with PDR. Immunoreactivity for KDR was abolished in a control specimen of PDR retina processed with omission of the primary antibody $(F)$. Magnification $=A, C, D \times 156 ; B \times 60 ; E$ $\times 118 ; F \times 78$.

with GFAP of bovine, rat, and human origin (Euro-Diagnostica), diluted $1 / 50$ in TBS. Negative controls were incubated with $0.2 \%$ goat serum in place of the primary antibody or substitution of the primary antibody with an inappropriate rabbit IgG at the same concentration as the primary antibody. Sections were washed three times with TBS and then incubated for 30 minutes with biotinylated goat anti-rabbit IgG (Sigma) and then incubated for 30 minutes with an avidin-biotin alkaline phosphatase reaction mixture (Dako Ltd). The sections were washed three times with TBS and then incubated with Fast Red AS-MX substrate (Sigma). hen the red colour had sufficiently developed counterstained with Mayer's haematoxylin.

ASSESSMENT OF IMMUNOSTAINING

The degree and pattern of immunostaining within and between specimens was assessed by standard light microscopy by two masked observers (both of whom obtained similar results). The intensity of staining was 
graded qualitatively as background (corresponding to the level of staining seen in the negative controls), weak, moderate, or intense (corresponding to the highest level of immunoreactivity), each of these being recorded as 0,1 , 2 , and 3 respectively. For each retinal specimen staining intensity was recorded for choroid, $\mathrm{RPE}$, photoreceptors, outer retina, inner retina, ganglion cell layer, and retinal vessels. For the fibrovascular membranes staining intensity was recorded for the vessels and the surrounding matrix. An average score was then calculated for each retinal layer within each group.

\section{Results}

Staining was observed in both non-diabetic and diabetic vascular and extravascular retinal tissue; increased immunostaining was observed in preretinal and intraretinal vessels of diabetic tissue compared with non-diabetic tissue (see Figs 1-4 and Tables 1-3). For all receptors variable staining of the vessels within each retina was observed with some vessels staining positive and some staining negative. In some instances staining was associated with both
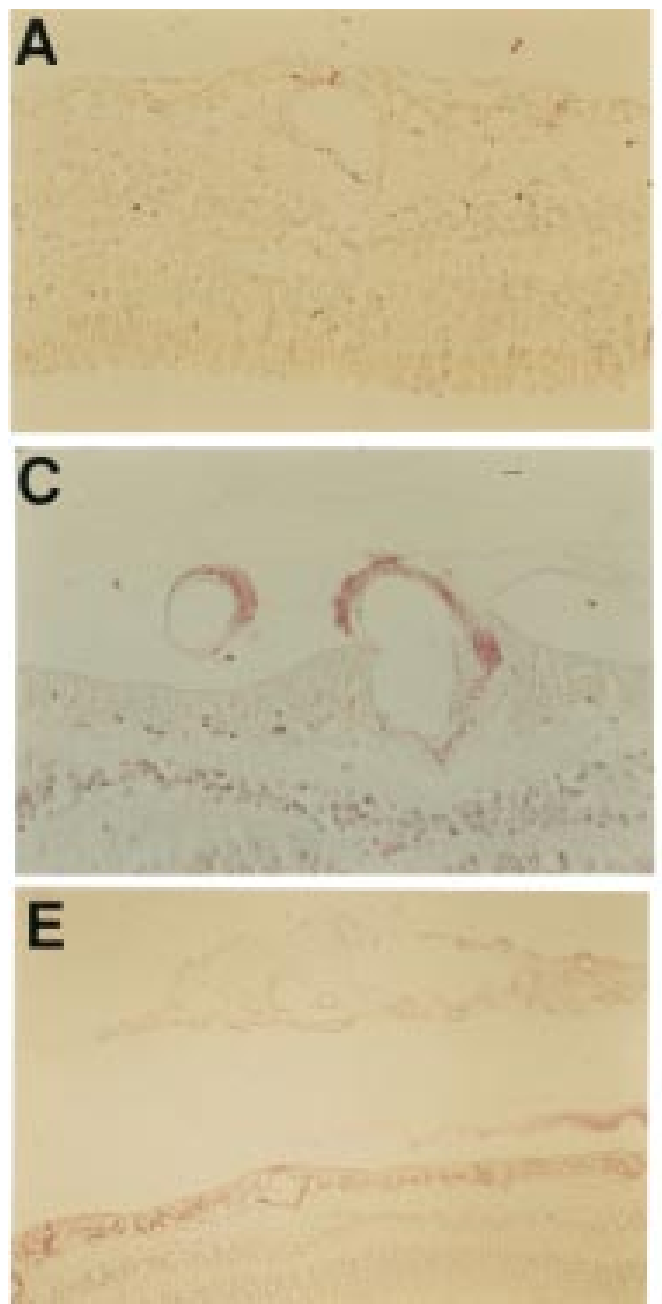

Figure 4 Photomicrographs demonstrating FLT-4 staining of normal retina $(A)$, diabetic retina with obvious vascular intraretinal changes but no evidence of $P D R(B)$, diabetic retina with $P D R(C, D)$ and the same retina stained with GFAP (E). Immunostaining for FLT-4 was raised in diabetic tissue compared with non-diabetic tissue. Immunostaining was intermediate in the PDR specimens. Immunoreactivity for FLT-4 was abolished in a control specimen of PDR retina processed with omission of the primary antibody $(F)$. Magnification $A, D \times 156 ; B \times 118 ; C \times 94 ; E, F \times 60$.

endothelial cells and the perivascular region of the vessels. The variability in staining within retinas of the same group did not show a correlation with donor age, the type of glycaemic control in the case of the diabetic groups, or time post mortem.

\section{FLT-1 IMMUNOREACTIVITY}

Staining intensity for FLT-1 was generally weak or absent in the choroidal vessels, the $\mathrm{RPE}$, and the photoreceptors. Weak staining was observed in the outer nuclear layer of most tissue categories but staining intensity tended to be elevated in diabetic eyes with vascular abnormalities and in those which had been successfully lasered. Weak to moderate staining was observed in the inner nuclear layer and weak to intense staining was observed in the ganglion cell layer of all the tissue categories including the non-diabetic eyes (Fig 1A-C; $\mathrm{E}-\mathrm{H}$; Table 1). The pattern of staining in the ganglion cell layer appeared to be associated with the Müller cell feet as it co-localised with positive GFAP staining (Fig 1D). While weak staining was observed in the retinal vessels of the non-diabetic eyes and the diabetic eyes
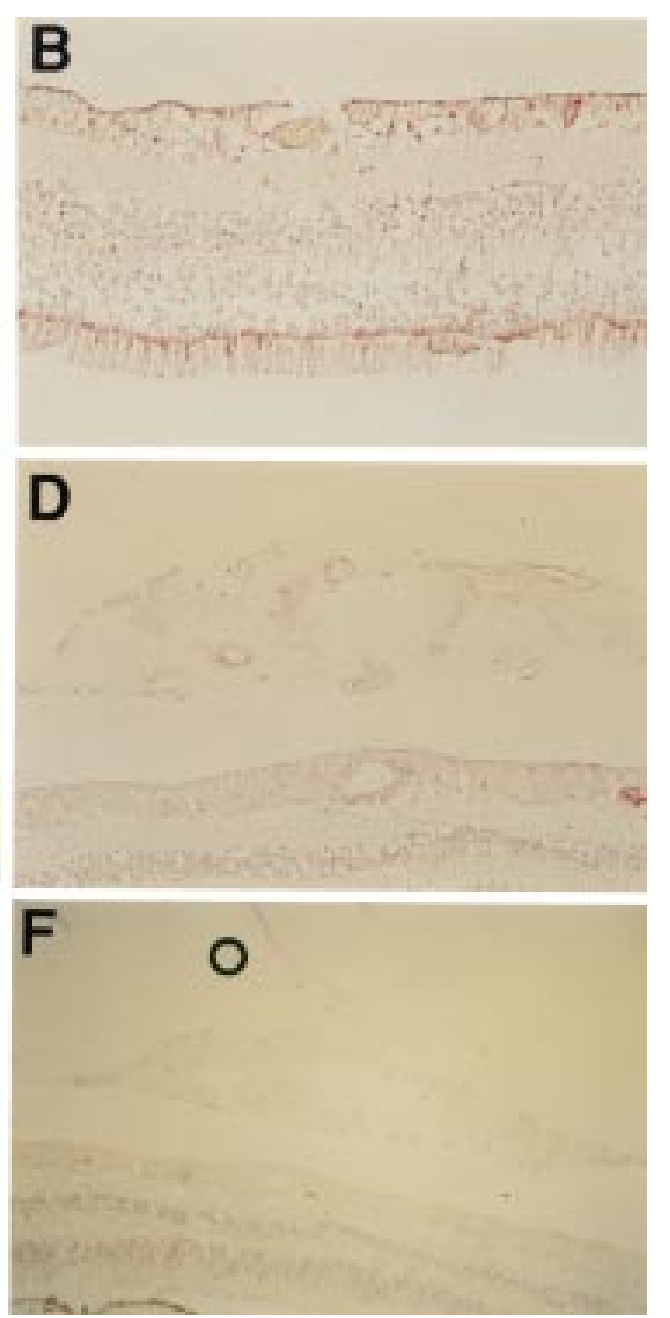
Table 1 Mean intensity (SD) of FLT-1 staining in the retina/choroid

\begin{tabular}{|c|c|c|c|c|c|c|c|c|c|}
\hline & Choroid & $R P E$ & $\begin{array}{l}\text { Photo } \\
\text { receptors }\end{array}$ & $\begin{array}{l}\text { Outer } \\
\text { nuclear layer }\end{array}$ & $\begin{array}{l}\text { Inner nuclear } \\
\text { layer }\end{array}$ & $\begin{array}{l}\text { Ganglion } \\
\text { cell layer }\end{array}$ & $\begin{array}{l}\text { Retinal } \\
\text { vessels }\end{array}$ & $\begin{array}{l}\text { Membrane } \\
\text { vessels }\end{array}$ & $\begin{array}{l}\text { Membrane } \\
\text { extravascular } \\
\text { matrix }\end{array}$ \\
\hline Non-diabetic $(n=10)$ & $0.70(0.46)$ & $1.10(0.83)$ & $0.60(0.80)$ & $0.20(0.40)$ & $1.10(0.94)$ & $1.50(1.12)$ & $1.0(1.0)$ & & \\
\hline No overt retinopathy $(n=12)$ & $0.92(0.64)$ & $0.58(0.86)$ & $0.42(0.49)$ & $0.33(0.47)$ & $1.42(0.49)$ & $1.92(0.86)$ & $1.25(0.92)$ & & \\
\hline Intraretinal changes $(n=5)$ & $0.60(0.80)$ & $0.80(0.75)$ & $0.80(1.17)$ & $1.20(1.17)$ & $1.60(0.80)$ & $2.20(0.75)$ & $1.60(1.02)$ & & \\
\hline $\operatorname{PDR}(n=6)$ & $1.0(0)$ & $0.17(0.37)$ & $0(0)$ & $1.0(0.82)$ & $1.17(0.69)$ & $2.0(0.82)$ & $1.50(1.12)$ & $2.50(0.50)$ & $1.17(0.37)$ \\
\hline Laser, no residual PDR $(\mathrm{n}=14)$ & $0.57(0.49)$ & $0.93(1.03)$ & $0.21(0.56)$ & $1.50(0.63)$ & $1.50(0.63)$ & $1.86(0.74)$ & $1.71(0.45)$ & & \\
\hline PDR excised membranes $(n=11)$ & & & & & & & & $1.55(0.78)$ & $1.09(0.79)$ \\
\hline
\end{tabular}

$0=$ background staining; $1=$ weak staining; 2 =moderate staining; $3=$ =intense staining.

without vascular changes, staining was moderate in all the other categories of diabetic tissue (Fig 1A-C; E-H; Table 1). The highest intensity of FLT-1 staining in the intraretinal vessels was associated with successful laser treatment with most (13/14) retinas staining. In all tissue categories staining tended to be confined to small and venous vessels in the superficial layers, although in 5/14 lasered retinas and in $2 / 6$ retinas with PDR (both of which had previously been lasered) staining of the arterial vessels was observed. The most intense staining for FLT-1 was observed in the vessels of preretinal membranes of the diabetic subjects who had PDR (Table 1). In this tissue category staining of the intraretinal vessels was associated both with the membranes and across the retina (Fig 1E, F, G) Staining was moderate in the excised membranes but staining tended to be confined to a proportion of the vessels within each membrane with $4 / 11$ of the membranes demonstrating staining both around the vessels and in the adjacent matrix (Fig 2A). Weak staining was associated with the nonvascular components of the membranes and staining with GPAP antibody confirmed that some of the perivascular and extravascular staining was glial cell in origin (Fig 2C).

\section{KDR IMMUNOREACTIVITY}

KDR immunoreactivity was generally minimal or absent in the choroidal vessels, the RPE, and the retinal layers of all the categories (Fig 3A); however, weak staining was observed in the inner nuclear layer and the ganglion cell layer of the unlasered eyes with obvious diabetic changes. Minimal to weak staining of the retinal vessels was observed in most categories but it became moderate to intense in the retinal vessels of diabetics with PDR with all (6/6) of the retinas staining (Fig 3B, C; Table 2). In 4/6 diabetic retinas with PDR staining of the intraretinal vessels was associated with the membranes but in $2 / 4$ of these staining was also observed in vessels across the retina. In all categories staining tended to be associated with small and venous vessels (with one exception which was a non-diabetic eye) and was always observed in the superficial retinal layers. Moderate staining of the preretinal vessels was observed in most of the membranes (Fig 3B, C). In some instances staining was observed in the perivascular region and extravascular region and staining with GFAP antibody confirmed this to be glial cell in origin (Fig 3D). In those retinas which had undergone apparently successful laser treatment staining was reduced (Fig 3E; Table 2). In the excised membranes staining tended to be confined to a proportion of the vessels within each membrane with $2 / 11$ of the membranes demonstrating staining both around the vessels and in the adjacent matrix. Weak or absent staining was associated with the non-vascular components of the membranes and staining with GFAP antibody confirmed that some of the perivascular and extravascular staining was glial cell in origin.

\section{FLT-4 IMMUNOREACTIVITY}

FLT-4 staining was absent or weak in the choroidal vessels, the RPE, the photoreceptors, and the outer nuclear layer in both non-

Table 2 Mean intensity (SD) of KDR staining in the retina/choroid

\begin{tabular}{|c|c|c|c|c|c|c|c|c|c|}
\hline & Choroid & $R P E$ & $\begin{array}{l}\text { Photo } \\
\text { receptors }\end{array}$ & $\begin{array}{l}\text { Outer } \\
\text { nuclear layer }\end{array}$ & $\begin{array}{l}\text { Inner nuclear } \\
\text { layer }\end{array}$ & $\begin{array}{l}\text { Ganglion cell } \\
\text { layer }\end{array}$ & $\begin{array}{l}\text { Retinal } \\
\text { vessels }\end{array}$ & $\begin{array}{l}\text { Membrane } \\
\text { vessels }\end{array}$ & $\begin{array}{l}\text { Membrane } \\
\text { extravascular } \\
\text { matrix }\end{array}$ \\
\hline Non-diabetic $(n=10)$ & $0.40(0.49)$ & $0.20(0.40)$ & $0.10(0.30)$ & $0.10(0.30)$ & $0.60(0.66)$ & $0.40(0.49)$ & $0.20(0.40)$ & & \\
\hline No overt retinopathy $(n=12)$ & $0.08(0.28)$ & $0(0)$ & $0.25(0.43)$ & $0(0)$ & $0.75(0.60)$ & $0.75(0.43)$ & $0.75(0.92)$ & & \\
\hline Intraretinal changes $(n=5)$ & $0.20(0.40)$ & $0(0)$ & $0.40(0.80)$ & $0(0)$ & $1.40(1.20)$ & $1.40(0.80)$ & $0.40(0.49)$ & & \\
\hline $\operatorname{PDR}(n=6)$ & $0.67(0.75)$ & $0(0)$ & $0(0)$ & $0(0)$ & $0.50(1.12)$ & $0.17(0.37)$ & $2.33(0.75)$ & $2.0(1.15)$ & $0.67(1.11)$ \\
\hline Laser, no residual PDR $(\mathrm{n}=14)$ & $0.07(0.26)$ & $0.07(0.26)$ & $0.07(0.26)$ & $0(0)$ & $0.71(0.45)$ & $0.29(0.45)$ & $0.50(0.82)$ & & \\
\hline PDR excised membranes $(n=11)$ & & & & & & & & $1.55(1.23)$ & $0.55(0.66)$ \\
\hline
\end{tabular}

0 =background staining; $1=$ weak staining; $2=$ moderate staining; $3=$ intense staining.

Table 3 Mean intensity (SD) of FLT-4 staining in the retina/choroid

\begin{tabular}{|c|c|c|c|c|c|c|c|c|c|}
\hline & Choroid & $R P E$ & $\begin{array}{l}\text { Photo } \\
\text { receptors }\end{array}$ & $\begin{array}{l}\text { Outer } \\
\text { nuclear layer }\end{array}$ & $\begin{array}{l}\text { Inner nuclear } \\
\text { layer }\end{array}$ & $\begin{array}{l}\text { Ganglion } \\
\text { cell layer }\end{array}$ & $\begin{array}{l}\text { Retinal } \\
\text { vessels }\end{array}$ & $\begin{array}{l}\text { Membrane } \\
\text { vessels }\end{array}$ & $\begin{array}{l}\text { Membrane } \\
\text { extravascular } \\
\text { matrix }\end{array}$ \\
\hline Non-diabetic $(n=10)$ & $0.30(0.46)$ & $0(0)$ & $0(0)$ & $0.10(0.30)$ & $0.90(0.94)$ & $0.50(0.67)$ & $0.70(1.0)$ & & \\
\hline No overt retinopathy $(n=12)$ & $0.42(0.49)$ & $0.08(0.28)$ & $0.33(0.75)$ & $0(0)$ & $1.50(0.76)$ & $1.83(0.80)$ & $1.0(0.71)$ & & \\
\hline Intraretinal changes $(n=5)$ & $0.20(0.40)$ & $0.20(0.40)$ & $0.60(0.80)$ & $0(0)$ & $1.80(1.17)$ & $2.0(1.10)$ & $1.20(1.47)$ & & \\
\hline $\operatorname{PDR}(n=6)$ & $1.0(0.82)$ & $0.17(0.37)$ & $0(0)$ & $0(0)$ & $0.33(0.47)$ & $1.0(0.82)$ & $1.50(1.12)$ & $1.50(1.26)$ & $0.33(0.47)$ \\
\hline Laser, no residual PDR $(\mathrm{n}=14)$ & $0.57(0.62)$ & $0.29(0.45)$ & $0.21(0.56)$ & $0.21(0.41)$ & $0.86(0.64)$ & $0.79(0.56)$ & $0.93(0.80)$ & & \\
\hline PDR excised membranes $(n=11)$ & & & & & & & & $1.73(0.96)$ & $0.18(0.39)$ \\
\hline
\end{tabular}

0 =background staining; 1 =weak staining; $2=$ moderate staining; $3=$ intense staining. 
diabetic retinas (Fig 4A) and diabetic retinas (Fig 4B, C, D). In the inner nuclear layer and the ganglion layer FLT-4 immunoreactivity was only raised in the unlasered eyes, after laser treatment the levels reduced (Table 3). Staining with GFAP antibody confirmed that FLT-4 staining was associated with glial cells of the retina (Fig 4E). In the retinal vessels FLT-4 staining was low except in the PDR specimens where staining was weak to moderate (Fig 4C, D). In this tissue category staining in the intraretinal vessels was associated with the membranes in 3/6 retinas but staining in $2 / 3$ of these was also observed in vessels across the retina. In all tissue categories staining tended to be associated with small and venous vessels of the superficial retinal layers although arterial staining was demonstrated in a small number of retinas. Weak to moderate staining was also observed in the preretinal vessels of the excised membranes. Staining tended to be associated with a proportion of vessels within each membrane with $2 / 11$ of the membranes demonstrating staining both around the vessels and in the adjacent matrix. Minimal staining was associated with the non-vascular components of the membranes and staining with GFAP antibody confirmed that some of the perivascular and extravascular staining was glial cell in origin.

\section{Discussion}

The data presented in this study demonstrate (a) immunolocalisation of FLT-1, KDR, and FLT-4 receptors to retinal tissue and (b) upregulation of these receptors in diabetic retinopathy. These observations add further support for a role for VEGF family members in the initiation and progression of PDR.

Binding sites for VEGF have previously been demonstrated to be associated with vascular endothelial cells during the development of the vasculature, ${ }^{17}{ }^{23-25}$ during pathological angiogenesis-for example, in healing wounds, in skin diseases, in hypersensitivity reactions, and in carcinomas, ${ }^{24}{ }^{26-29}$ and from in vitro studies. ${ }^{70-37}$ These observations advance a regulatory role for VEGF and its receptors in angiogenesis occurring both during normal vascular development and in various pathologies.

The observation in this study that $\mathrm{KDR}$ is greatly elevated in both intra- and preretinal vessels in PDR tissue and minimal in normal retina and the quiescent vessels of lasered diabetic retina with no evidence of PDR is in agreement with the view that KDR is involved in pathological angiogenesis. These findings correlate with the findings of various workers $^{38-40}$ who reported high levels of VEGF in the vitreous of patients with active PDR. By contrast, FLT-1 was observed in both nondiabetic and diabetic vascular and avascular retinal tissue. The presence of FLT-1 in non-diabetic tissue may reflect its involvement in metabolic control-for example, control of vessel permeability and endothelial cell maintenance. Upregulation of FLT-1 in diabetic vessels, particularly those undergoing active neovascularisation, indicates that the receptor plays a role in PDR. Firstly, it may induce vascular leakage; FLT-1 is known to promote vascular permeability. ${ }^{5}$ Secondly, it has been suggested that it may participate in VEGF induced mitogenesis by heterodimer formation with KDR. ${ }^{41}$ Thirdly, FLT-1 may regulate VEGF induced angiogenesis; a soluble form of FLT-1 can complex with the extracellular region of KDR and act as a negative regulator of VEGF action. ${ }^{37}$ Fourthly, PlGF which is associated with PDR acts through the FLT-1 receptor. ${ }^{20}$ FLT-4 represents a third putative receptor for the VEGF family which shares structural similarities with FLT-1 and KDR; it is believed to be a receptor for VEGF-C. ${ }^{42}$ FLT-4 immunolocalisation was minimal in non-diabetic eyes but was upregulated in diabetic tissue, especially in the inner nuclear layer, the ganglion cell layer, and intraretinal and preretinal vessels. These observations suggest that FLT-4 may have a role in the pathogenesis of diabetic retinopathy.

Several ocular cell types, in addition to vascular endothelial cells $s^{3344}$ and pericytes, $^{75}$ express VEGF receptors. VEGF receptors have been identified on cultured corneal cells, ${ }^{46}$ cultured lens epithelial cells, ${ }^{47} 48$ and cultured RPE cells. ${ }^{48}{ }^{49}$ Increased levels of VEGF mRNA and protein have previously been demonstrated in retinal disorders in the cell bodies of the inner nuclear layer, the ganglion cell layer, and the outer nuclear layer. ${ }^{89131516}$ Studies on the developing retinal vasculature have also demonstrated VEGF mRNA and protein in the retinal glial cells. ${ }^{50}{ }^{51}$ Chen and co-workers demonstrated intense VEGF staining in both vascular and extravascular epiretinal membranes. ${ }^{49}$ They also demonstrated FLT-1 but not KDR expression by glial cells in the epiretinal membranes and in cultured retinal glial cells. In our study we also demonstrated increased immunoreactivity for FLT-1, FLT-4, and, to a lesser extent, KDR in the glial cells of the retina which was particularly associated with the end feet of the Müller cells. Thus, these observations demonstrate that VEGF may act through its receptors via both autocrine and paracrine mechanisms. It may be that one of the functions of the retinal glial cells is as early detectors of the hypoxic environment occurring during the earlier stages of diabetic retinopathy. This could explain why in our study FLT-1, FLT-4, and to a lesser extent KDR, were associated with the glial cells before proliferation had occurred. These cells may respond to hypoxia by upregulating their receptors and secreting VEGF which acts on the endothelial cells. The sustained production of VEGF would eventually lead to an angiogenic response. Sustained production of VEGF may be maintained by a positive feedback mechanism to the receptors on the glial cells and the endothelial cells which could explain why increased levels of FLT-1 were observed in the glial cells of the eyes with PDR. An interesting observation was that in some of the membranes GFAP staining was observed both around the vessels and in the surrounding matrix which corresponded to receptor immunoreactivity. It may be that these particular membranes were undergoing active 
neovascularisation or that there may have been hypoxic regions within these membranes.

VEGF receptor expression appears to be regulated by various stimuli including growth factors and cytokines ${ }^{5}$ and, as mentioned above, hypoxia. ${ }^{73} 344445$ Takagi et al suggested that hypoxia may be responsible for increasing $\mathrm{KDR} / \mathrm{FLK}$ expression indirectly via adenosine receptors on endothelial cells ${ }^{44}$; adenosine is hypoxia inducible in some tissues and it is known to stimulate angiogenesis and cellular proliferation.

In conclusion, this study confirms the presence of VEGF family receptors in the diabetic retina and indicates that while KDR appears to be involved principally with the angiogenic process (that is, PDR), FLT-1 may have a role in both normal endothelial cell homeostasis and in all stages of diabetic retinopathy. Therefore, any agent directed against VEGF or FLT-1 could have a detrimental effect on the normal structure and functioning of endothelial cells and vessels. A more attractive alternative would be to produce antiangiogenic molecule(s) with low toxicity directed against KDR. One study by Strawn and co-workers found anti-angiogenesis compounds that can inhibit FLK-1/KDR tyrosine kinase activity as well as endothelial cell mitogenesis and blood vessel formation in the chorioallantoic membrane. ${ }^{52}$ Further studies are necessary (a) to determine whether the receptors are active, (b) to ascertain the stimulus for upregulation of the receptors, and (c) to determine whether inhibition of receptor activation is the therapy of choice in preretinal angiogenesis.

This work was supported by the British Diabetic Association, The Guide Dogs for the Blind Association, and the Mancheste Royal Eye Hospital Endowment Fund.

1 Boulton M, McLeod D, Garner A. Vasoproliferative retinopathies: clinical, morphogenetic and modulatory retinopathies: clinical, morphogenet

2 Ferrara N. The role of vascular endothelial growth factor in pathological angiogenesis. Breast Cancer Research and Treatment 1995;36:127-37.

3 Ferrara N. Vascular endothelial growth factor. The trigger for neovascularization in the eye. Lab Invest 1995;72:61518.

4 Thomas KA. Vascular endothelial growth factor, a potent and selective angiogenic agent. F Biol Chem 1996;271:6036.

5 Kolch W, Martiny-Baron G, Kieser A, et al. Regulation of the expression of the VEGF/VPS and its receptors: role in tumor angiogenesis. Breast Cancer Research and Treatment 1995;36:139-55.

6 Ferrara N, Houck KA, Jakeman LB, et al. The vascular endothelial growth factor family of polypeptides. $7 \mathrm{Cell} \mathrm{Bio-}$ chem 1991;46:211-18.

7 Nomura M, Yamagishi S, Harada S, et al. Possible participation of autocrine and paracrine vascular endothelial growth tion of autocrine and paracrine vascular endothelial growth factors in hypoxia-induced proliferation of endo
and pericytes. 7 Biol Chem 1995;270:28316-24.

8 Pe'er J, Shweiki D, Itin A, et al. Hypoxia-induced expression of vascular endothelial growth factor by retinal cells is a common factor in neovascularizing ocular diseases. $\mathrm{Lab}$ Invest 1995;72:638-45.

9 Pierce EA, Avery RL, Foley ED, et al. Vascular endothelial growth factor/vascular permeability factor expression in a mouse model of retinal neovascularization. Proc Natl Acad Sci USA 1995;92:905-9.

10 Aiello LP, Pierce EA, Foley ED, et al. Suppression of retinal neovascularization in vivo by inhibition of vascular
endothelial growth factor (VEGF) using soluble VEGFreceptor chimeric proteins. Proc Natl Acad Sci USA 1995;92:10457-61.

11 Adamis AP, Shima DT, Tolentino MJ, et al. Inhibition of vascular endothelial growth factor prevents retinal ischaemia-associated iris neovascularization in a nonhuman primate. Arch Ophthalmol 1996;114:66-71.

12 Murata T, Ishibashi T, Khalil A, H et al. Vascular endothelial growth factor plays a role in hyperpermeability of diabetic retinal vessels. Ophthalmic Res 1995;27:48-52.
13 Pe'er J, Folberg R, Itin A, et al. Upregulated expression of vascular endothelial growth factor in proliferative diabetic vascular endothelial growth factor in prolife
retinopathy. $B r \mathcal{F}$ Ophthalmol 1996;80:241-5.

14 Lutty GA, McLeod DS, Merges C, et al. Localization of vascular endothelial growth factor in human retina and choroid. Arch Ophthalmol 1996;114:971-7.

15 Amin RH, Frank RN, Kennedy A, et al. Vascular endothelial growth factor is present in glial cells of the retina and optic nerve of human subjects with non proliferative diabetic retinopathy. Invest Ophthalmol Vis Sci 1997;38:36-47.

16 Boulton M, Foreman D, Williams G, et al. VEGF localisation in diabetic retinopathy. Br F Ophthalmol 1998; 82:561-8.

17 Millauer B, Wizigmann-Voos S, Schnurch H, et al. High affinity VEGF binding and developmental expression suggest Flk-1 as a major regulator of vasculogenesis and angiogenesis. Cell 1993;72:835-46.

18 Breier G, Clauss M, Risau W. Coordinate expression of vascular endothelial growth factor receptor-1(ftt-1) and its ligand suggests a paracrine regulation of murine vascular development. Developmental Dynamics 1995;204:228-39.

19 Khaliq A, Foreman D, Ahmed A, et al. Increased expression of placenta growth factor (PLGF) in proliferative diabetic retinopathy. Lab Invest 1998;78:109-16.

20 Sawano A, Takahashi T, Yamaguchi S, et al. Flt-1 but not KDR/FLK-1 tyrosine kinase is a receptor for placenta growth factor, which is related to vascular endothelial growth factor, which is related to vascular 1 .

21 Galland F, Karamysheva A, Pebusque M, et al. The FLT4 gene encodes a transmembrane tyrosine kinase related to the vascular endothelial growth factor receptor. Oncogene 1993;8:1233-40.

22 Borg J, deLapeyriere O, Tetsuro N, et al. Biochemical characterization of two isoforms of FLT4, a VEGF receptorrelated tyrosine kinase. Oncogene 1995;10:973-84.

23 Oelrichs RB, Reid HH, Bernard O, et al. NYK/FLK-1: a putative receptor protein tyrosine kinase isolated from E10 embryonic neuroepithelium is expressed in endothelial cells of the developing embryo. Oncogene 1993;8:11-18.

24 Peters KG, De Vries C, Williams LT. Vascular endothelial growth factor receptor expression during embryogenesis and tissue repair suggests a role in endothelial differentiation and blood vessel growth. Proc Natl Acad Sci USA 1993;90:8915-19.

25 Quinn TP, Peters KG, De Vries C, et al. Fetal liver kinase 1 is a receptor for vascular endothelial growth factor and is selectively expressed in vascular endothelium. Proc Natl Acad Sci USA 1993;90:7533-7.

26 Detmar M, Brown LF, Claffey KP, et al. Overexpression of vascular permeability factor/vascular endothelial growth factor and its receptors in psoriasis. 7 Exp Med 1994:180: 1141-6.

27 Boocock CA, Charnock-Jones DS, Sharkey AM, et al. Expression of vascular endothelial growth factor and its receptors flt and KDR in ovarian carcinoma. $\mathcal{F}$ Natl Cancer Inst 1995;87:506-16.

28 Brown LF, Olbricht SM, Berse B, et al. Overexpression of vascular permeability factor (VPF/VEGF) and its endothelial cell receptors in delayed hypersensitivity skin reactions. f Immunol 1995;154:2801-7.

29 Christofori G, Naik P, Hanahan D. Vascular endothelial growth factor and its receptors, flt-1 and flk-1, are expressed in normal pancreatic islets and throughout islet cell tumorigenesis. Mol Endocrinol 1995;9:1760-70.

30 Vaisman N, Gospodarowicz D, Neufield G. Characterization of the receptors for vascular endothelial growth factor. f Biol Chem 1990;265:19461-6.

31 Jakeman LB, Winer J, Bennet GL, et al. Binding sites for vascular endothelial growth factor are localised on endothelial cells in adult rat tissues. $f$ Clin Invest 1992;89:244-53.

32 Terman BI, Khandke L, Dougher-Vermazan M, et al. VEGF receptor subtypes KDR and FLT-1 show different sensitivities to heparin and placenta growth factor. Growth Factors 1994;11:187-95.

33 Thieme H, Aiello LP, Takagi H, et al. Comparative analysis of vascular endothelial growth factor receptors on retinal and aortic vascular endothelial cells. Diabetes 1995;44:98103.

34 Brogi E, Schatteman G, Wu T, et al. Hypoxia induced paracrine regulation of vascular endothelial growth factor crine regulation of vascular endothelial growth

35 Gitay-Goren H, Cohen T, Tessler S, et al. Selective binding of VEGF121 to one of three vascular endothelial growth of VEGF121 to one of three vascular endothelial growth 1996;271:5519-23.

36 Hewett PW, Murray JC. Coexpression of flt-1, flt-4 and $\mathrm{KDR}$ in freshly isolated and cultured human endothelial cells. Biochem Biophys Res Comm 1996;221:697-702.

37 Kendall RL, Wang G, Thomas KA. Identification of a natural soluble form of the vascular endothelial growth factor receptor, FLT-1, and its heterodimerization with KDR. Biochem Biophys Res Comm 1996;226:324-8.

38 Adamis AP, Miller JW, Bernal M, et al. Increased vascular endothelial growth factor levels in the vitreous of eyes with proliferative diabetic retinopathy. Am $\mathcal{F}$ Ophthalmol 1994; 118: $445-50$

39 Aiello LP, Avery RL, Arrigg PG, et al. Vascular endothelial growth factor in ocular fluid of patients with diabetic retinopathy and other retinal disorders. N Engl f Med 1994;331: $1480-7$.

40 Malecaze F, Clamens S, Simorre-Pinatel V, et al. Detection of vascular endothelial growth factor messenger RNA and vas- 
cular endothelial growth factor-like activity in proliferative diabetic retinopathy. Arch Ophthalmol 1994;112:1476-82.

41 Waltenberger J, Claesson-Welsh L, Siegbahn A, et al. Different signal transduction properties of KDR and Flt1, two receptors for vascular endothelial growth factor. $\mathcal{F} \mathrm{Biol}$ Chem 1994;269:26988-95.

42 Joukov V, Pajusola K, Kaipainan A, et al. A novel vascula endothelial growth factor, VEGF-C, is a ligand for Flt4 (VEGFR-3) and KDR (VEGFR-2) receptor tyrosine kinases. $E M B O \mathcal{F} 1996 ; 15: 290-8$

43 Simorre-Pinatel V, Guerrin M, Chollet $\mathrm{P}$, et al. Vasculotropin-VEGF stimulates retinal capillary endothelial cells through an autocrine pathway. Ophthalmol Vis $\mathrm{Sci}$ 1994;35:3393-400.

44 Takagi H, King GL, Ferrara N, et al. Hypoxia regulates vascular endothelial growth factor receptor $\mathrm{KDR} / \mathrm{Flk}$ gene expression through adenosine A2 receptors in retinal capillary endothelial cells. Invest Ophthalmol Vis Sci 1996;37: 1311-21.

45 Takagi H, King GL, Aiello LP. Identification and characterization of vascular endothelial growth factor receptor (FLT) zation of vascular endothelial growth factor receptor (F
in bovine retinal pericytes. Diabetes 1996;45:1016-23.

46 Gitay-Goren H, Soker S, Vlodavsky I, et al. The binding of vascular endothelial growth factor to its receptors is dependent on cell surface-associated heparin-like molecules. F Biol Chem 1992;267:6093-8

47 Neufield G, Tessler S, Gitay-Goran H, et al. Vascular endothelial growth factor and its receptors. Progress Growth Factor Res 1994;5:89-97.

48 Guerrin M, Moukadiri H, Chollet P, et al. Vasculotropin/ vascular endothelial growth factor is an autocrine growth factor for human retinal pigment epithelial cells cultured in vivo. 7 Cell Physiol 1995;164:385-94.

49 Chen Y, Hackett SF, Schoenfeld C, et al. Localisation of vascular endothelial growth factor and its receptors to cells of vascular and avascular epiretinal membranes. $\mathrm{Br} \mathcal{F} \mathrm{Oph}-$ thalmol 1997;81:919-26.

50 Murata T, Nakagawa K, Khalil A, et al. The temporal and spatial vascular endothelial growth factor expression in retinal vasculogenesis of rat neonates. Lab Invest 1996;74: $68-77$.

51 Stone J, Itin A, Alon T, et al. Development of retinal vascularature is mediated by hypoxia-induced vascular endothelial growth factor (VEGF) expression by neuroglia. 7 Neurosc 1995;15:4738-47.

52 Strawn LM, McMahon G, App H, et al. Flk-1 as a target for tumour growth inhibition. Cancer Res 1996;56:3540-5. 